\title{
Cisplatin/Fluorouracil/Cetuximab Regimen
}

National Cancer Institute

\section{Source}

National Cancer Institute. Cisplatin/Fluorouracil/Cetuximab Regimen. NCI Thesaurus.

Code C150691.

A chemoimmunotherapy regimen consisting of cisplatin, fluorouracil (5-FU) and cetuximab used for the treatment of various types of head and neck cancer. 